\title{
A pesquisa em etnobotânica e o retorno do conhecimento sistematizado à comunidade: um assunto complexo
}

\author{
Research in ethnobotany and the return of systematized \\ knowledge to the community: a complex issue
}

\section{Rubia Graciela Patzlaff \\ Bióloga e mestre em botânica pela Escola Nacional de Botânica Tropical/ Instituto de Pesquisas Jardim Botânico do Rio de Janeiro \\ rubiagpatz@gmail.com}

\section{Ariane Luna Peixoto}

Pesquisadora associada do Instituto de Pesquisas Jardim Botânico do Rio de Janeiro

Escola Nacional de Botânica Tropical Rua Pacheco Leão, 2.040

22460-038 Rio de Janeiro - RJ

Brasil

ariane@jbrj.gov.br
PATZLAFF, Rubia Graciela; PEIXOTO, Ariane Luna. A pesquisa em etnobotânica e o retorno do conhecimento sistematizado à comunidade: um assunto complexo. História, Ciências, SaúdeManguinhos, Rio de Janeiro, v.16, n.1, jan.-mar. 2009, p.237-246.

Resumo

Como retornar o saber investigado em pesquisa etnobotânica ao meio social no qual ele foi gerado? O que deve ser levado à comunidade? Essas perguntas motivaram o acompanhamento de duas pesquisas etnobotânicas e suas respectivas propostas de como retornar à comunidade o conhecimento associado às plantas, sistematizado pelo cientista. É usual a devolução dos dados da pesquisa à comunidade na forma de manuais ou cartilhas, listas ilustradas de plantas, palestras e cursos. Entretanto, têm-se elaborado outras formas que caracterizam troca de saberes entre o cientista e a comunidade, com ganhos mútuos. A presente pesquisa corrobora essas alternativas e sugere que a definição das atividades de retorno do conhecimento à comunidade, mesmo proposto e acordado no início da pesquisa, seja flexível, possibilitando a inclusão de novas demandas nascidas durante a execução da pesquisa.

Palavras-chave: etnobotânica; conhecimento tradicional; retorno; plantas medicinais.

\section{Abstract}

How should information gathered in ethnobotanical research be returned to the social environment where it was generated? What should be taken to the community? These questions motivated the accompaniment of two ethnobotanical studies and their respective proposals for how to return to the community the knowledge associated to plants, systematized by the scientist. It is common for research data to be returned to a community by means of manuals, information booklets, illustrated lists of plants, lectures and courses. Nevertheless, other forms have been prepared that characterize an exchange of knowledge among the scientist and the community, with mutual gains. This study corroborates these alternatives and suggests that the definition of the activities to return knowledge to the community, even that proposed and agreed to at the beginning of the study, be flexible, allowing the inclusion of new needs that arise during the execution of the study.

Keywords: ethnobotany; traditional knowledge; return; medicinal plants. 
A etnobotânica é o estudo das sociedades humanas, passadas e presentes, e suas interações ecológicas, genéticas, evolutivas, simbólicas e culturais com as plantas (Alexiades, 1996). Aplicada ao estudo de plantas medicinais, a etnobotânica trabalha em estreita cumplicidade com outras disciplinas correlatas como, por exemplo, a etnofarmacologia: "Como estratégia na investigação de plantas medicinais, a abordagem etnofarmacológica consiste em combinar informações adquiridas junto a usuários da flora medicinal (comunidades e especialistas tradicionais), com estudos químicos e farmacológicos" (Elizabetsky, 2003, p.35).

No contexto da investigação etnobotânica, o pesquisador procura conhecer a cultura e o dia-a-dia da comunidade pesquisada, os conceitos locais de doença/saúde, o modo como a comunidade se vale dos recursos naturais para a 'cura' de seus males, atrair ou afastar animais, construir habitações mais adequadas ao local e outros. Ele procura repassar o conhecimento apreendido para o meio científico sem incorrer em erros de interpretação. É recomendado que a sua relação com a comunidade não entre no campo do envolvimento pessoal. Entretanto, freqüentemente a barreira de pesquisador/pesquisado é ultrapassada e vínculos afetivos são criados, sobretudo com os indivíduos que mais usualmente acompanham o pesquisador no contato com a comunidade e, quando necessário, nas florestas, hortas ou quintais onde se encontram as plantas utilizadas.

O pesquisador olha a comunidade como um espaço de aprendizagem e, de modo geral, procura mostrar que está aí para aprender e trocar conhecimentos. No momento em que se insere no cotidiano local e atende aos preceitos anteriormente assinalados, o pesquisador passa a contar com o respeito da comunidade e é nesse espaço de respeito mútuo que o saber local pode ser mais bem apreendido, entendido e posteriormente relatado em crônicas e textos científicos (Amorozo, 1996). No Brasil, a literatura é farta de relatos de viajantes e cientistas que, desde os primeiros séculos após o descobrimento e até hoje, mostraram o quanto comunidades locais conhecem sobre as plantas e seus usos (Lima, 1952). Entretanto, também há riscos nessas atividades. Há relatos de viajantes e pesquisadores que se apaixonaram pela comunidade estudada, por sua cultura, se identificando de tal forma com ela, que abandonaram a vida até então construída, passando a inserir-se na comunidade. Por outro lado, há também alguns relatos de dificuldades de relacionamento entre pesquisador/comunidade ou na definição de estratégias ou produtos que retornam à comunidade pesquisada (Rodrigues, Assimakopoulos, Carlini, 2005).

Há muitos indicativos de que, no contexto da pesquisa etnobotânica, retribuir a comunidade pelo acolhimento, respeito e ajuda na pesquisa, mas especialmente pelo compartilhamento do saber sobre as plantas tem sido uma preocupação dos cientistas. Essa preocupação se tornou, entretanto, mais explícita, após a promulgação da Convenção sobre a Diversidade Biológica (CDB), firmada em 1992 por 162 países, entre os quais o Brasil. A CDB estabelece três níveis de obrigações a serem cumpridas por cada país participante: a conservação da diversidade biológica, a utilização sustentável de seus componentes e a repartição de benefícios derivados da utilização dos recursos genéticos (Albagli, 2006). Após a promulgação da CDB e, predominantemente, após a publicação da medida provisória 2.186-16, em 2001 - que dispõe sobre o acesso ao patrimônio genético, a proteção e o acesso ao conhecimento tradicional associado, a repartição de benefícios 
bem como o acesso à tecnologia e transferência de tecnologia para sua conservação e utilização -, a discussão do tema tem-se desdobrado, tomando como foco predominantemente questões éticas e de regulamentação (Markus, Rodrigues, 2003; Ming et al., 2005). O presente texto não tem como foco principal esses dois aspectos.

Tomando como base dois estudos etnobotânicos realizados, ele descreve e analisa a forma como se procedeu o retorno do conhecimento apreendido pelos pesquisadores às comunidades pesquisadas, e a troca de saberes entre pesquisadores/comunidades, numa relação de parceria.

\section{Qual é a melhor maneira de levar os resultados das investigações para o meio social no qual elas se iniciaram?}

A questão do retorno, embora antiga, tomou força principalmente diante dos compromissos da sociedade com conservação, uso sustentável e repartição de benefícios derivados da utilização da biodiversidade, especialmente em países megadiversos. ${ }^{1}$

Caballero (1983) sugere que a etnobotânica deixe de ser um exercício acadêmico e coloquese a serviço das comunidades fonte das informações. Nesse sentido, Martin (1986) enfatiza que a própria comunidade deve participar do desenvolvimento da pesquisa, pois o fazer etnobotânico promoverá a conservação e o desenvolvimento dos recursos naturais, o desenvolvimento cultural e a execução de tarefas derivadas da investigação, como, por exemplo, a formação de hortas medicinais empregadas pela própria comunidade. Formas de retorno das informações às comunidades usuárias e conhecedoras de plantas medicinais foram discutidas também por Elisabetsky (1987), Martin (1995) e Alexiades (1996), que afirmam que o estudo deve beneficiar de alguma forma as pessoas envolvidas, individualmente e/ou em comunidade. Jorge e Morais (2003) afirmam que a devolução elaborada dos dados oriundos da pesquisa etnobotânica às populações de origem pode contribuir para que esses conhecimentos, seus informantes, suas comunidades e as espécies por eles utilizadas sejam mais bem compreendidos e valorizados. Em artigo que discute ética na pesquisa científica, predominantemente em antropologia, elaborado por Debert (2003), encontra-se a mesma preocupação, "ganha centralidade nos debates que a disciplina [antropologia] atualmente vem promovendo, o tema dos modos de restituição aos sujeitos pesquisados do saber que construímos a partir deles. Devem eles ter acesso em primeira mão à obra produzida?" (p.30). Essa mesma autora informa que a antropologia foi a primeira disciplina das ciências humanas a elaborar um código de ética.

Em etnobotânica, a forma mais usual de retorno do saber construído pelo cientista a partir das informações obtidas na comunidade tem sido a devolução dos dados sistematizados, ou seja, a devolução dos dados da pesquisa na forma de manuais, cartilhas, painéis expositivos, folders e similares (Fonseca-Kruel et al., 2006; Patzlaf, Peixoto, 2007), além da entrega de cópias de artigos formalmente publicados, dissertações e teses. Entretanto, outras formas têm sido propostas em projetos ou praticadas, tais como o registro das histórias que estavam quase esquecidas ou que são do domínio de poucos (Garrote, 2004), a confecção de material didático para escolas da região a partir dos resultados da pesquisa (Jorge, Morais, 2003), mapas georrefenciados apontando as florestas e cursos d'água utilizados pela 
comunidade (Soler, comunicação pessoal), fotografias de famílias, da vegetação e das plantas locais (Blanckaert et al., 2004; Soler, comunicação pessoal), implantação de hortas medicinais (Boscolo, 2003), entre outras.

No presente texto são analisadas e discutidas propostas de retorno do conhecimento às comunidades realizado em duas pesquisas etnobotânicas. Esta análise foi motivada pelas seguintes questões: O que retornar à comunidade e qual a melhor forma de fazê-lo? A elaboração da proposta de retorno do conhecimento à comunidade deve partir de quem? A proposta do retorno deve estar clara já na elaboração do projeto ou pode ser elaborada durante a convivência com a comunidade?

O objetivo desta discussão é estimular o debate, levando estudantes e pesquisadores a refletir sobre o tema de modo a aprimorar mecanismos que sejam proveitosos e benéficos, tanto aos informantes e colaboradores que contribuíram com os seus saberes, individualmente ou em grupo (a comunidade), quanto aos cientistas, sem a pretensão de propor regras para a condução dessa atividade.

\section{Estudo de casos}

Patzlaff (2007), ao planejar a pesquisa Estudos Etnobotânicos de Plantas de Uso Medicinal e Místico na Comunidade da Capoeira Grande, Pedra de Guaratiba, Rio de Janeiro (RJ) Brasil, explicitou, em seu projeto, que após a realização do trabalho, juntamente com a comunidade, elaboraria uma forma de retorno do saber construído para a comunidade. O projeto foi apresentado à comunidade, na sede da Associação de Moradores da Capoeira Grande, com ela discutido, sendo formalizado, então, o consentimento para o desenvolvimento da pesquisa. Iniciado o trabalho de campo, após três meses em contato com a Associação de Moradores e com a comunidade local, foi-lhe solicitado colaborar na elaboração de um projeto de horto, incluindo neste um jardim de plantas medicinais. Ainda na mesma pesquisa, uma comunidade vizinha (Jardim Cinco Marias, Pedra de Guaratiba), que através do Programa de Fitoterapia do município do Rio de Janeiro estava iniciando a formação de um grupo de estudos sediado no Módulo do Programa de Saúde da Família (PSF), solicitou a sua colaboração na identificação das plantas que a comunidade utilizava. Essa colaboração levou-a à participação em reuniões na comunidade e ao estabelecimento de um jardim de plantas medicinais. O convite se estendeu à sua participação em um curso sobre identificação e utilização de plantas medicinais. Um fato de destaque é que o curso era ministrado por uma senhora da própria comunidade, considerada por eles uma autoridade no assunto e, nesse tema, respeitada por todos. Do curso participaram os agentes de saúde e uma enfermeira do módulo do PSF, além de outras pessoas da comunidade (Figura 1). Convidaram-na também para, junto com mulheres vinculadas ao PSF, compor uma equipe que apresentaria atividades vinculadas ao uso de plantas em um stand, dentro das atividades da Semana Nacional de Ciência e Tecnologia (SNCT), na praça principal de Pedra de Guaratiba, em 2006. Esse convite foi renovado, em 2007, quando os resultados da pesquisa foram apresentados e discutidos, em uma palestra, na tenda climatizada da SNCT, em Guaratiba.

Verifica-se então que: (a) o retorno da pesquisa à comunidade foi requerido antes mesmo de a pesquisadora sugeri-lo ou ter a oportunidade de consultar os líderes e a comunidade sobre o assunto; quando ocorre fato como esse, o trabalho do pesquisador é facilitado; (b) 
o tempo de convivência de três meses foi suficiente para criar um vínculo de confiança e de intimidade, que permitiu à comunidade tomar a iniciativa de buscar a colaboração da pesquisadora (a pesquisa de campo se estendeu por 18 meses); (c) o trabalho realizado na comunidade estudada e na comunidade vizinha foi suficiente para sua aceitação, que se desdobrou na solicitação de colaboração com o grupo de estudos de fitoterapia; (d) a comunidade demonstrou ter aceitado a pesquisadora como um dos seus, pois a convidou para um curso direcionado a pessoas da localidade ou parceiros definidos com uma finalidade estabelecida, ministrado por uma pessoa respeitada localmente.

Soler (2005), ao planejar a sua pesquisa Levantamento Florístico e Etnobotânico em um Hectare de Floresta de Terra Firme na Região do Médio Rio Negro (RR), Brasil, (publicado sob a forma de dois artigos: Soler, Peixoto, 2007, 2008), optou, como forma de retorno do saber apreendido na comunidade pesquisada, pela elaboração de uma listagem de espécies da floresta, ordenadas por nomes comuns e dados sobre o uso informado pela comunidade. O projeto foi apresentado à comunidade, que se autodefine como cabocla, na única escola da localidade. Nessa ocasião, foi formalizado o consentimento da comunidade para o desenvolvimento da pesquisa e feita a indicação dos informantes, por ela considerados detentores de maior saber sobre as espécies da floresta local.

Ao final da pesquisa, a listagem das espécies foi entregue à comunidade. No entanto, na percepção do pesquisador, suas maiores contribuições à comunidade e que, aparentemente, foram assim também avaliadas por ela foram: (a) jogar capoeira com crianças e jovens, ao final do dia de campo, durante os três meses vividos na comunidade, usando as músicas e os movimentos como oportunidade para compartilhar vivências sobre conservação de espécies e de conhecimento local; (b) um mapa colorido da região, copiado em papel e plastificado, com a localização da comunidade e assinalando os cursos d'água e a floresta, acompanhando uma legenda descritiva, para ser afixado na escola; (c) diversas fotografias de moradores em suas atividades do cotidiano (confecção de paneiros e esteiras, lavagem de roupa no rio, produção de farinha etc.) e do conjunto de crianças da escola local (Figura 2); (d) aulas de inglês ministradas para alguns caboclos que desejavam ter mais facilidade de comunicação com turistas que algumas vezes visitam a região. Pode-se acrescer que a convivência prolongada e diária do pesquisador e o compartilhamento do dia-a-dia, desde a pesca para a própria alimentação às longas caminhadas na floresta, tornaram mais visível para a comunidade que há um saber local sobre as plantas e seu uso que é valorizado também fora da comunidade (Soler, comunicação pessoal).

Verifica-se que o pesquisador elaborou sua forma de devolução dos dados oriundos da pesquisa etnobotânica idealizando uma situação que acreditava ser valiosa para a comunidade. Entretanto, durante a pesquisa, ao ter um contato mais próximo com a comunidade, dividir suas experiência e ouvir as deles, reconheceu necessidades e interesses locais mais imediatos e distintos daqueles que havia idealizado. Usando o seu lastro de 'cultura formal', teve possibilidade de jogar capoeira com crianças e adolescentes e dividir outros conhecimentos que possuía. Atendeu às solicitações da comunidade, sem, entretanto, abrir mão do seu planejamento inicial. Em argüições feitas para o presente texto, o pesquisador assim se manifestou: 


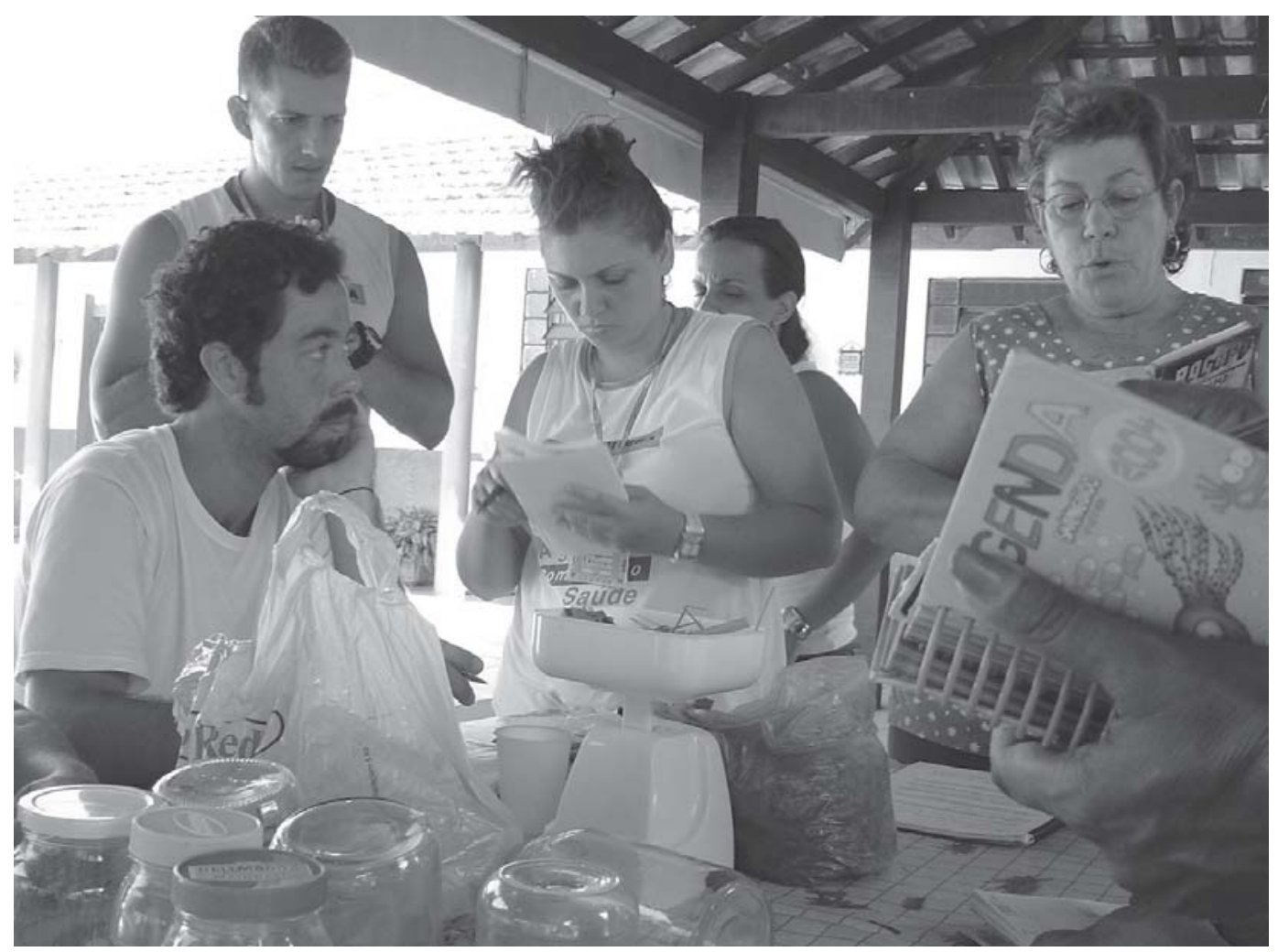

Figura 1 - Curso de Manipulação de Plantas Medicinais, oferecido por dona Márcia (à direita) a agentes de saúde do Módulo de Saúde do Programa de Saúde da Família (PSF) e à comunidade do Jardim Cinco Marias, Pedra de Guaratiba, Rio de Janeiro (RJ) (foto R.G. Patzlaff)

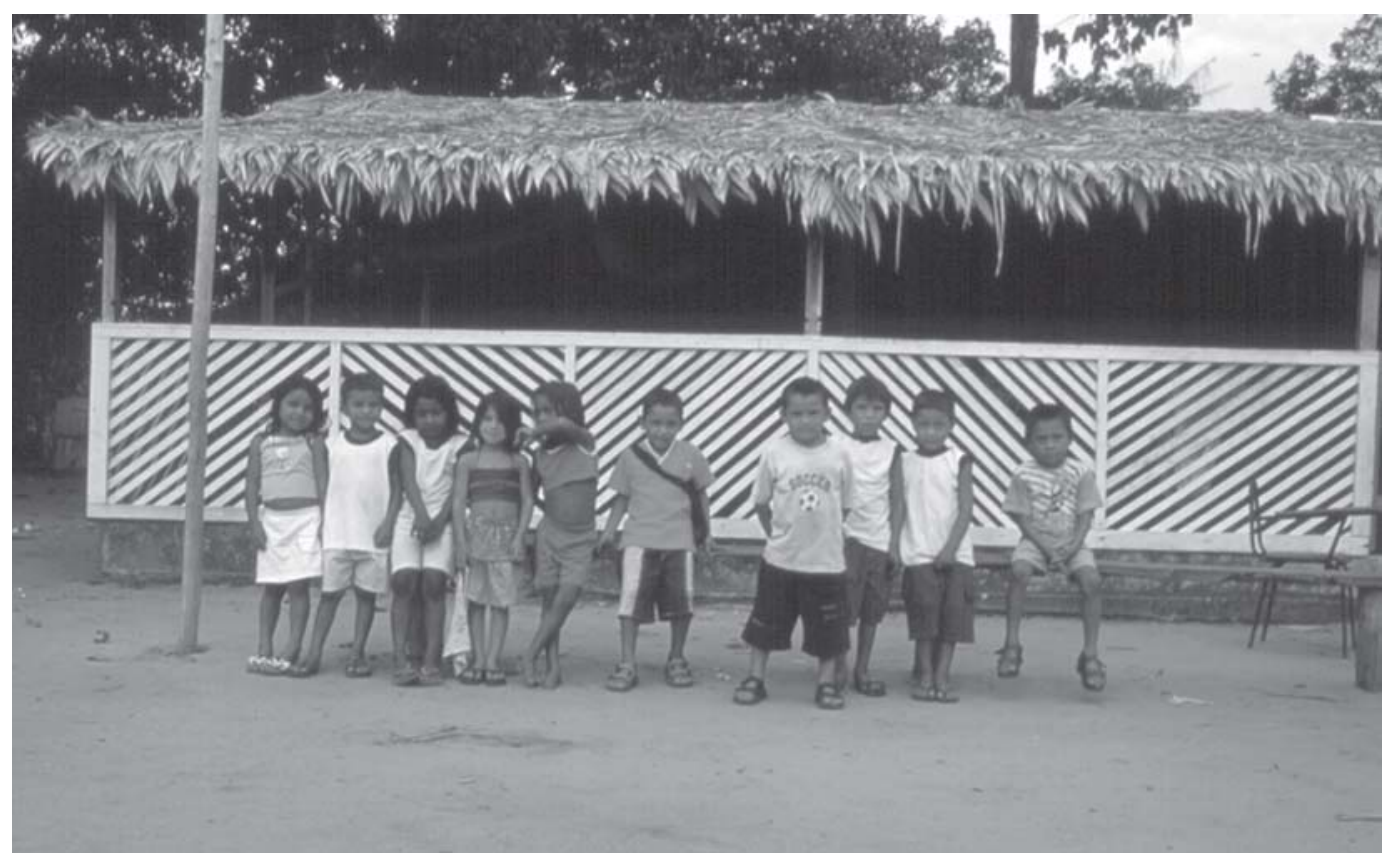

Figura 2 - Crianças diante da escola, Vila de Caicubi, Caracaraí (RR) (foto J G. Soler) 
Eu apresentei para a comunidade todo o resultado da pesquisa feita e deixei a listagem comentada, além de mapas e fotografias. Senti, na apresentação feita em forma de palestra, que havia pessoas que não entendiam e pareciam não interessadas pelo assunto. Estavam presentes àquele encontro pelos laços e compromissos que se haviam estabelecido desde o início da pesquisa. Hoje, analisando aquele momento, reconheço que deveria ter utilizado uma linguagem mais simples. Porém considero a apresentação dos resultados à comunidade um ato importante. Afirmo ainda que a comunidade local pode não perceber de imediato a importância dos resultados que se obtêm em trabalho com etnobotânica. Entretanto eles devem ser deixados e expostos localmente, pois no futuro podem se tornar documentos valiosos para a comunidade. É importante deixar os documentos com vários líderes locais, pois eles podem compartilhá-los com lideranças de outras comunidades. Os resultados podem ser úteis também para outras comunidades que estejam vivenciando outro momento em seu desenvolvimento e estejam interessadas na conservação de recursos biológicos e do saber local. O desenvolvimento dos projetos e seus resultados podem ser úteis desde a obtenção de seus resultados ou a longo prazo (Soler, comunicação pessoal).

\section{Discussão e considerações}

Os casos descritos mostram que, algumas vezes, as demandas e solicitações das comunidades tornam-se mais imediatas do que os compromissos formalmente assumidos no projeto de pesquisa anteriormente formulado e acordado quando da sua apresentação à comunidade. Entretanto, para os cientistas envolvidos nessas pesquisas, as solicitações apresentadas pela comunidade e atendidas total ou parcialmente, antes da finalização da pesquisa, não substituíram e nem comprometeram a atividade planejada em seu início.

A valorização dos saberes dos informantes pelos pesquisadores foi importante, nos dois casos relatados, para a aceitação e reconhecimento dos saberes dos pesquisadores pelas comunidades. Estimular o auto-reconhecimento dos informantes como especialistas em determinado tema (conhecedor de plantas medicinais, conhecedor de árvores da floresta) e o reconhecimento por pares é importante para a auto-estima dos informantes e da comunidade, fortalece a unidade da comunidade. Além disso, a participação na pesquisa propicia o resgate de saberes pouco ou não valorizados e, em algumas situações, 'esquecidos" pelo próprio informante, mas que estavam na memória de algumas pessoas, e ainda contribui para a manutenção dos saberes da comunidade na própria comunidade. Patzlaff (2007) transcreve falas dos especialistas locais, relatando esses saberes; Soler e Peixoto (2008) informam que $98 \%$ das espécies arbóreas do trecho de floresta estudado eram conhecidas e apontadas como de alguma utilidade pelos especialistas locais.

Posey (1986, p.167) alerta que "os informantes podem ser especialistas de uma determinada área de conhecimento dentro de sua própria cultura e, portanto, devem ser tratados com o mesmo respeito que dispensamos aos especialistas em nossa própria cultura". O pesquisador está coletando informações, ouvindo e aprendendo com eles sobre determinados temas cuja vivência no local já os tornou especialistas e, portanto, querem ser respeitados como tal.

Alexiades (1996) salienta que uma compensação precisa ser feita quando há um uso extensivo do tempo e da experiência das pessoas locais, sendo interessante discutir com as contrapartes, sua liderança e com organizações de pesquisa o que seria um bom retorno. 
No entanto, o tipo de compensação irá variar em forma, de área para área e também dependendo do tipo da pesquisa. Em relação aos dois casos aqui descritos, tanto para Soler (2005) como para Patzlaff (2007), houve a necessidade de aprimoramento do planejamento inicial, adaptando-o às novas demandas apresentadas pelas comunidades e que nem sempre estavam inteiramente ligadas ao tema de suas pesquisas. Tal fato mostra que a convivência com a comunidade é de extrema importância para o reconhecimento de suas necessidades e interesses e que estes devem ser considerados no momento da elaboração do retorno, sem entretanto se perder de vista uma perspectiva futura do uso dos resultados formais da pesquisa realizada.

Alexiades (1996) chama também a atenção para outro tipo de retorno que o pesquisador pode dar para a comunidade em estudo: o reconhecimento intelectual. Esse reconhecimento pode ser vantajoso e/ou desejado pela comunidade. Em alguns casos, um informante ou toda a comunidade pode requerer esse reconhecimento, como ocorrido na comunidade Mutitjulu (Baker, Mutitjulu Community, 1992); em outros, dependendo da pesquisa, o anonimato é requerido e preferido em relação ao reconhecimento público. Quando e como esse reconhecimento deve ser feito, ou ainda se é desejável, também deve ser discutido com a comunidade e sua liderança. A menos que o anonimato seja requerido, esse reconhecimento deve ser realizado de forma apropriada. O acordo de Melaka (Asomps, 1994) sugere, entre outras coisas, que editores de periódicos e revisores de artigos devam garantir que o devido reconhecimento seja realizado pelos pesquisadores em seus artigos. Não tem sido rara, em pesquisas etnobotânicas, a participação de membros das comunidades entre os autores de manuais ou cartilhas para uso na própria comunidade. Fonseca-Kruel et al. (2006) ilustram esse procedimento.

As duas experiências relatadas, cotejadas com extensa literatura, corroboram as alternativas do retorno do saber construído a partir de informações obtidas em comunidades locais para estas mesmas comunidades, distintas (porém não excludentes) daquelas mais usualmente apontados quando da elaboração dos projetos de pesquisa.

Mostram também que cada comunidade tem características próprias que devem ser levadas em consideração no momento de elaboração da proposta de retorno do saber construído, sendo portanto difícil estabelecer a priori uma metodologia. É indispensável, entretanto, apontar-se, no planejamento e na apresentação da proposta à comunidade, possíveis caminhos a serem buscados para que a comunidade também aprenda com a pesquisa realizada. Reafirmam que o retorno elaborado dos dados oriundos da pesquisa etnobotânica à comunidade é uma das formas de reconhecimento pela ajuda e pelo tempo despendido, e, principalmente, pelo compartilhamento do saber.

Sugere-se que a proposta de devolução do saber construído à comunidade, apresentada no início da pesquisa, não tenha predomínio sobre outras formas que possam surgir no desenvolvimento do trabalho e na convivência com a comunidade, enfatizando que essa convivência é de vital importância em pesquisas etnobotânicas.

\section{AGRADECIMENTOS}

A Juan Gabriel Soler Alarcon pela discussão de diferentes etapas de suas pesquisas, compartilhando as experiências vividas, e a Inês Machline Silva pela leitura crítica do manuscrito. 


\section{NOTA}

${ }^{1}$ Os 12 países que compõem o grupo dos megadiversos são Brasil, China, México, Índia, Colômbia, Venezuela, Peru, Costa Rica, Equador, África do Sul, Quênia e Indonésia. Esses países possuem cerca de 70\% da biodiversidade mundial. O Brasil é o mais rico deles; detém cerca de $20 \%$ do número total de espécies do planeta e possui a flora mais rica, com cerca de 56 mil espécies de fanerógamos (plantas superiores) descritas, ou 22\% do total mundial (Mittermeier et al., 1999).

\section{REFERÊNCIAS}

ALBAGLI, Sarita.

Convenção sobre diversidade biológica: uma visão a partir do Brasil. In: Garay, Irene; Becker, Bertha K. (Org.). Dimensões humanas da biodiversidade: o desafio de novas relações sociedade-natureza no século XXI. Rio de Janeiro: Vozes. p.113-134. 2006.

ALEXIADES, Miguel.

Selected guidelines for ethnobotanical research: a field manual. New York: New York Botanical Garden. 1996.

AMOrOzO, Maria Christina Mello. Abordagem etnobotânica na pesquisa de plantas medicinais. In: Di Stasi, Luis Claudio (Org.). Plantas medicinais: arte e ciência - um guia de estudo interdisciplinar. São Paulo: Unesp. p.47-68. 1996.

\section{ASOMPS.}

Asian Symposium on Medicinal Plants, Spices, and Other Natural Products. The Melaka Accord towards the development of legislation to protect biodiversity. Kuala Lumpur: University Pertanian Malaysia. 1994.

BAKER, Lynn M.; MUTITJULU COMMUNITY. Comparing two views of the landscape: aboriginal ecological knowledge and modern scientific knowledge. Rangeland Journal, Cottesloe, v.14, n.2, p.174-189. 1992.

BLANCKAERT, Isabelle et al.

Floristic composition, plant uses management practices in homegardens of San Rafael Coxcatlán, Valley of Tehuacán-Cuicatlán, México. Journal of Arid Environments, Chubut, v.57, p.39-62. 2004.

\section{BOSCOLO, Odara Horta.}

Estudos etnobotânicos no município de Quissamã, Rio de Janeiro (RJ). Dissertação (Mestrado) Museu Nacional, Universidade Federal do Rio de Janeiro, Rio de Janeiro. 2003.

CABALLERO, Javier.

Perspectiva para el quehacer etnobotânico em México. In: Barrera, A. (Ed.). La etnobotânica: três puntos de vista e una perspectiva. Xalapa: Instituto Nacional de Investigaciones sobre Recursos Bióticos. p.25-28. 1983.
DEBERT, Guita Grin.

Poder e ética na pesquisa social. Ciência e Cultura, Campinas, v.55, n.3, p.30-32. 2003.

ELISABETSKY, Elaine.

Etnofarmacologia. Ciência e Cultura,

Campinas, v.55, n.3, p.35-36. 2003.

ELISABETSKY, Elaine.

Etnofarmacologia de algumas tribos brasileiras. In: Ribeiro, Berta (Org.). Suma etnológica brasileira. v.1: Etnobiologia. Petrópolis: Vozes. p.135-148. 1987.

FONSECA-KRUEL, Viviane Stern et al. Plantas úteis da restinga: o saber dos pescadores artesanais de Arraial do Cabo (RJ). Rio de Janeiro: Jardim Botânico do Rio de Janeiro. 2006.

GARROTE, Valquíria.

Os quintais caiçaras, suas características sócioambientais e perspectivas para a comunidade do Saco do Mamanguá, Paraty (RJ). Dissertação (Mestrado) - Escola Superior de Agricultura Luiz de Queiroz, Piracicaba. 2004.

JORGE, Schirlei da Silva Alves; MORAIS, Ronan Gil de. Etnobotânica de plantas medicinais. In: Coelho, M.F.B., Costa Júnior, P.; Dombroski, J.L.D. (Org.). Diversos olhares em etnobiologia, etnoecologia e plantas medicinais. Seminário de Etnobiologia, Etnoecologia, 1. e Seminário Centro-Oeste de Plantas Medicinais, 2. Anais... . Cuiabá: Ed. Unicem. p.89-98. 2003.

LIMA, Américo Pires.

O conde de Hoffmansegg e a flora do Brasil. Anais da Faculdade de Farmácia do Porto, Porto, v.12, p.5-20. 1952.

MARKUS, Regina Pekelmann; RODRIGUES, Miguel Trefaut Rodrigues.

Biodiversidade: haverá um mapa para este tesouro? Ciência e Cultura, Campinas, v.55, n.3, p.20-21. 2003.

\section{MARTIN, Gary J.}

Ethnobotany: a methods manual. London: Chapman \& Hall. 1995.

MARTIN, Gary J.

El papel de la etnobotânica en el resgate 
ecológico y cultural de America Latina. Congresso Latino Americano de Botânica. Simpósio de Etnobotânica, 4. Medelin. Anais... . S.l.: s.n. p.67-77. 1986.

MING, Lin Chau et al. (Org.).

Direitos de recursos tradicionais: formas de proteção e repartição de benefícios. Botucatu: Unesp; SBEE. 2005.

MITTERMEIER, Russel A. et al. (Ed.). Hotspots: earth's biologically richest and most endangered terrestrial ecoregions. Mexico City: Cemex/Agrupación Sierra Madre. 1999.

PATZLAFF, Rubia Graciele.

Estudo etnobotânico de plantas de uso medicinal e místico na comunidade da Capoeira Grande, Pedra de Guaratiba (RJ) Brasil. Dissertação (Mestrado) - Instituto de Pesquisas Jardim Botânico do Rio de Janeiro, Escola Nacional de Botânica Tropical, Rio de Janeiro. 2007.

PATZLAFF, Rubia Graciele; PEIXOTO, Ariane Luna.

O conhecimento sobre plantas de uso medicinal na Capoeira Grande, Pedra de Guaratiba. Rio de Janeiro: Instituto de Pesquisas Jardim Botânico do Rio de Janeiro, Escola Nacional de Botânica Tropical. Folder. 2007.

POSEY, Darrell Addison.

Ethnoentomology of the Kaiapó indians of central Brazil. Journal of Ethnobiology, Philadelphia, v.1, n.1, p.165-74. 1986.

RODRIGUES, Eliane; ASSIMAKOPOULOS, Cristina T.; CARLINI, Elisaldo A.

Conhecimento tradicional e repartição de benefícios: o caso dos índios Krahô. In: Ming, Lin Chau et al. (Org.). Direitos de recursos tradicionais: formas de proteção e repartição de benefícios. Botucatu: Unesp; SBEE. p.115-147. 2005.

SOLER, Juan Gabriel.

Levantamento florístico e etnobotânico em um hectare de floresta de terra firme na região do Médio Rio Negro (RR) Brasil. Dissertação (Mestrado) - Escola Nacional de Botânica Tropical, Jardim Botânico do Rio de Janeiro, Rio de Janeiro. 2005.

SOLER, Juan Gabriel; PEIXOTO, Ariane Luna. Use of Terra Firme forest by Caicubi caboclos, Middle Rio Negro, Amazonas, Brazil: a quantitative study. Economic Botany, New York, v.62, p.60-73. 2008.

SOLER, Juan Gabriel; PEIXOTO, Ariane Luna. Florística e fitossociologia de um trecho de um hectare de floresta de terra firme, em Caracaraí (RR) Brasil. Boletim do Museu Paraense Emílio Goeldi, Belém, v.2, n.2, p.33-60. (Série Ciências Naturais). 2007.

\section{$\rightarrow \rightarrow+<<$}

